ISSN 2227-7102

www.mdpi.com/journal/education

Article

\title{
Reliability and Validity of the Multidimensional Scale of Life Skills in Late Childhood
}

\author{
Minoru Kobayashi ${ }^{1}{ }_{*}$, Taichi Gushiken ${ }^{2}$, Yurika Ganaha ${ }^{2}$, Yosiaki Sasazawa ${ }^{2}$, \\ Shotaro Iwata $^{3}$, Akiko Takemura ${ }^{2}$, Tsutomu Fujita ${ }^{4}$, Yonathan Asikin ${ }^{5}$ and \\ Minoru Takakura ${ }^{6}$
}

1 Educational Support Center, Kyoto University of Education, 1 Fujinomori-cho, Fukakusa, Fushimiku, Kyoto 612-8522, Japan; E-Mail: mkoba98@kyokyo-u.ac.jp

2 Faculty of Education, University of the Ryukyus, 1 Senbaru, Nishihara-cho, Nakagami, Okinawa 903-0213, Japan; E-Mails: nankuru68@ @otmail.co.jp (T.G.); yganaha@edu.u-ryukyu.ac.jp (Y.G.); sasazawa@edu.u-ryukyu.ac.jp (Y.S.), hangiojin@yahoo.co.jp (A.T.)

3 Graduate School of Education, Hiroshima University, 1-1-1 Kagamiyama, Higashi-Hiroshima city, Hiroshima 839-8524, Japan; E-Mail: ishotaro@hiroshima-u.ac.jp

4 Faculty of Education, Kagoshima University, 1-20-6 Korimoto, Kagoshima 890-0065, Japan; E-Mail: t-fujita@edu.kagoshima-u.ac.jp

5 Faculty of Life Sciences, Swiss German University, Edu Town BSD City, Kav. II.1, Tangerang 15339, Indonesia; E-Mails: yonathan.asikin@sgu.ac.id; yonathan.asikin@gmail.com

6 Faculty of Medicine, University of the Ryukyus, 207 Uehara, Nakagami, Okinawa 903-0125, Japan; E-Mail: minoru@med.u-ryukyu.ac.jp

* Author to whom correspondence to be addressed: E-mail: mkoba98@kyokyo-u.ac.jp; Tel./Fax: +81-75-644-8229.

Received: 7 September 2012; in revised form: 27 March 2013 / Accepted: 2 April 2013 / Published: 12 April 2013

Abstract: This study investigated the reliability and validity of the Multidimensional Scale of
Life Skills in Late Childhood, an instrument designed to measure a concept similar to "zest for
living" in late childhood. A total of 1,888 elementary school students in the 4th, 5 th, and 6th
grades residing in urban and suburban areas as well as in remote islands of 3 prefectures
(Okinawa, Kagoshima, and Nagasaki) were surveyed. On the basis of our analysis, 24
items and seven factors were extracted. These factors are problem-solving/synthesis,
relationship with friends, personal manners, decision-making and future planning, self- 
learning, collecting and using information, and leadership. Cronbach's alpha reliability coefficients were computed for each subscale and ranged from 0.71 to 0.87 . Test-retest reliability coefficient values ranged from 0.68 to 0.79 . To examine the construct validity of the scales, a goodness-of-fit model was determined by confirmatory factor analysis, and satisfactory values were found $(\mathrm{GFI}=0.952$, AGFI $=0.937, \mathrm{CFI}=0.966$, RMSEA $=$ 0.016). The validity of the goodness-of-fit model and the reliability of the scales indicate that the Multidimensional Scale of Life Skills in Late Childhood is an effective assessment tool.

Keywords: life skills; "zest for living"; multidimensional scale; late childhood

\section{Introduction}

According to a study by the Elementary and Secondary Education Bureau of the Japanese Ministry of Education, Culture, Sports, Science and Technology, students in upper-grade elementary school and junior high school frequently have behavioral problems [1], including absences from class and bullying. The numbers of reported absences from class of upper-grade elementary school students (4th, 5th, and 6th grades) of 2007 school year were 4,102, 5,980, and 8,145, respectively, and the numbers of reported absences of junior high school students (1st, 2nd, and 3rd grades) were 25,120, 37,714, and 42,494 , respectively. The numbers of bullying cases in upper-grade elementary schools were 8,784 , 10,376, and 9,903, respectively, and in junior high school 21,077, 14,872, and 7,556, respectively. The overall student population for students in all grades was approximately 1.2 million students. Moreover, problems in "relationships with other people and friends" were reported as the main reason for absence from class (more than 50\%). Iida and Ishikuma [2] reported that lacking daily life skills is a cause of behavioral problems. Instruments to assess children's life skills have been developed by many researchers, and psychological measurement scales are a focus of the World Health Organization (WHO) [3].

In the USA and European countries, the Test for Everyday Living (TEL) is used as a scale to measure life skills [4]. This test assesses a wide range of behaviors and skills needed in daily life, and it is considered an initial step in the research on developing scales to measure life skills [2]. The Life Skills Scale was first developed in 1984 and proposed four categories of life skills: interpersonal communication and human relationship skills, problem-solving and decision-making skills, physical fitness and health maintenance skills, and personal development and goal-setting skills [5]. From this framework, life-skills-measurement scales have been developed for use with ordinary young people [6], delinquent young people [7], children and adults [8], and college or university students [9].

Measurement of life skills has been studied for many years. In 1995, Danish, Petitpas, and Hale [10] established the basic definition of life skills, and Ueno and Nakagomi [11] have endorsed the use of a measurement scale of life skills. This scale was prepared to assess students' daily lives with subscales for personal skills (eight items) and interpersonal skills (ten items), including some items that relate to athletic skills. Brooks [5] proposed a life-skills framework that generally corresponded with the Life Skills Development Scale-Adolescent Form (LSDS-B), a 65-item version by Darden, 
Ginter, and Gazda [6]. Iida and Ishikuma also proposed a measurement scale of life skills for junior high school students [12]. This scale was developed using a framework of developmental and physiological factors relating to students' school lives, and consisted of five subscales: communication, self-learning, decision-making, teamwork, and health. However, Iida and Ishikuma [12] focused on only general factors that are directly related to improvement of students' skills, and psychological or emotional factors were not clearly measured. In addition, Shimamoto and Ishii [9] reported a measurement scale of life skills for university students comprising eight subscales and 24 items measuring planning, knowledge summarization, self-esteem, positive thinking, intimacy, leadership, empathy, and interpersonal manners. In this scale, the "internal workings of the mind necessary for effective living" were evaluated with respect to students' general behavior. Thus, in assessing comprehensive life skills, psychological and emotional factors should be included and considered as playing a key role in developing overall skills [13].

"Zest for living" (ikiruchikara) was originally considered a part of the social life and culture of Japanese people. It has become a key point in the philosophy of Japanese teaching. Historically, Japan has been working to standardize the quality of its formal education system. In practical life, students who cannot achieve the standards of academic achievement are likely to have difficulty living as members of society. Thus, a major emphasis has been on fostering a "zest for living" in children, a term that was officially proposed by the Japanese Ministry of Education, Culture, Sports, Science and Technology in 1998. In the Japanese version of $21^{\text {st }}$ century skills, "zest for living" seeks to promote the qualities and abilities necessary to steadily acquire the basics of education and to have self-learning abilities, as well as to develop problem-solving skills and to acquire skills for relating with others. Since March 2008, "zest for living" has been promoted in new courses of study in Japanese elementary and junior high schools. Some of its defining features are "an ability to learn, think, judge and act on their own and to solve a problem"; "enriched humanity with self-discipline, cooperative personality, and kindness and care toward others"; and "health and physical strength for a better life," and it is recognized as one of the core philosophies in the Japanese educational system [14]. This concept is similar to the concept of ten life skills promoted by the WHO [3]. Furthermore, Minagawa [15] reported that these life skills and "zest for living" are comparable. However, the concept of "zest for living" is better recognized in Japan than the concept of life skills [15, 16]; accordingly, Iishi and Shimamoto [9] have developed a multidimensional scale of life skills, including psychological and emotional factors, which is very close in meaning to the concept of "zest for living." In order to solve children's behavioral problems at an early stage, it is very important develop an applicable concept of life skills. Although a multidimensional scale of life skills for university students has been developed [9], to our knowledge, a scale addressing the other developmental stages has not been reported.

Although "zest for living" has been promoted by the Japanese Ministry of Education, Culture, Sports, Science and Technology since 2008 [17], understanding of the concept, especially among school officials and parents, and implementation of related studies is still lacking. It is not clear which factors correlate with the concept of "zest for living" in various developmental stages. Hence, in order to solve the present educational challenges, several key factors were considered when developing a multidimensional scale of life skills. The aim of the present study was to investigate the reliability and validity of a scale of multidimensional life skills in late childhood, with particular consideration for skills that relate to the concept of "zest for living." The definition of multidimensional life skills used in this 
study was "internal workings of the mind necessary for effective living" [9], and the children were school-aged children ranging from 6 to 12 years old or students in the 4th, 5th, and 6th grades [18].

\section{Methodology and Research Design}

\subsection{Survey Respondents}

Respondents of this study were 4th, 5th, and 6th graders from elementary schools in urban and suburban areas, as well as from remote islands of three prefectures (Okinawa, Kagoshima, and Nagasaki). The respondents were 924 male students and 964 female students whose ages averaged $10.3 \pm 0.94$ years. Our response rate was $79.6 \%$ (Table 1); 488 children (male and female) who were surveyed did not respond.

Table 1. Respondent classification.

\begin{tabular}{|c|c|c|c|c|c|c|c|c|c|c|c|c|}
\hline \multirow{3}{*}{ Prefecture } & \multicolumn{6}{|c|}{ Urban and suburban areas } & \multicolumn{6}{|c|}{ Remote island area } \\
\hline & \multicolumn{2}{|c|}{ 4th grade } & \multicolumn{2}{|c|}{ 5th grade } & \multicolumn{2}{|c|}{ 6th grade } & \multicolumn{2}{|c|}{ 4th grade } & \multicolumn{2}{|c|}{ 5th grade } & \multicolumn{2}{|c|}{ 6th grade } \\
\hline & Boy & Girl & Boy & Girl & Boy & Girl & Boy & Girl & Boy & Girl & Boy & Girl \\
\hline Okinawa & 29 & 31 & 27 & 30 & 28 & 36 & 57 & 69 & 46 & 49 & 50 & 48 \\
\hline Kagoshima & 52 & 64 & 53 & 58 & 67 & 65 & 14 & 11 & 16 & 20 & 30 & 17 \\
\hline Nagasaki & 38 & 44 & 48 & 44 & 27 & 23 & 112 & 119 & 124 & 99 & 106 & 137 \\
\hline
\end{tabular}

For the test-retest method, 228 students from two schools in urban and suburban areas of Okinawa Prefecture were surveyed at an interval of approximately one week. Of these results, 141 responses were excluded from the analysis because of missing or wrong answers (59 boys and 82 girls with an average age of $10.4 \pm 0.90$ years, for a response rate of $61.8 \%$ ). Moreover, 87 respondents with incomplete answers were also excluded from the analysis. All surveys were conducted with ethical considerations; respondents' participation was voluntary and permission was obtained.

\subsection{Study Period and Procedure}

The study period was from 3-18 July 2008. The study was conducted using a survey method with permission from school principals or vice principals, and classroom teachers then carried out the data collection. Exploratory factor analysis (maximum likelihood method and promax rotation) was conducted, and all data were then analyzed statistically using SPSS 16.0 at a significance level of 5\%.

\subsection{Survey Methods}

Subjects reported their grade, age, and gender and completed the survey concerning their daily life (life skills). Each question was answered on a scale of 1 to 5 , where $1=$ never (not true) and $5=$ always (very true) as it related to each behavior or action.

The survey consisted of 60 items measuring planning ability (three items), collecting and using information (three items), self-respect (three items), positive thinking (three items), empathy (three items), leadership (three items), sensitivity (three items), personal manners (three items), interpersonal communication and human relations (ten items), problem-solving and decision-making (seven items), 
physical fitness and health (six items), self-learning (three items), and career decision-making (three items). The Multidimensional Scale of Life Skills in Late Childhood was then developed from these factors, similar to previously reported life-skill scales for university students [9] and its LSDS-B [6], and junior high school students [12].

\subsection{Content Validity}

Three elementary school teachers (each having 15-20 years of teaching experience), one university student majoring in elementary education teaching, and one graduate student majoring in pedagogy examined the items for each subscale. All items were reviewed with regard to suitability for children of the targeted developmental stage, appropriateness for measuring life skills in late childhood, and appropriateness of the terms to avoid confusing or overlapping meanings.

A qualitative review process was conducted by experts in a group discussion, in which all 60 subscale items were carefully evaluated for semantic content relevant to "zest of living" in children. Other decisive factors were qualities and abilities necessary to steadily acquire a basic education, to have selflearning abilities, to develop problem-solving skills, and to naturally acquire the skills for relating with others. Finally, all items had to fit within the context of children's physical and mental health.

\subsection{Item Analysis}

To examine item discrimination, scores of each item were compared by $t$-test scores for each independent item of the respondent. The overall mean scores and standard deviation of the total assessment value of each item were classified into $25 \%$ superior scores and $25 \%$ inferior scores as the upper scoring group (I: 476 respondents) and the lower scoring group (II: 481 respondents), respectively.

The discrimination evaluation of significant differences in scores between items in each group revealed satisfactory values (Table 2). Therefore, a factorial analysis of the 60 items was conducted.

Table 2. Discrimination of each item in upper and lower scoring groups.

\begin{tabular}{|c|c|c|c|c|c|c|c|c|}
\hline \multirow{3}{*}{$\frac{\text { Life skill }}{\text { Q1 }}$} & \multirow{3}{*}{$\begin{array}{r}\boldsymbol{M} \\
3.3\end{array}$} & \multirow{3}{*}{\begin{aligned} \multicolumn{1}{l}{$S \boldsymbol{D}$} \\
1.12\end{aligned}} & \multicolumn{2}{|c|}{ Group I } & \multicolumn{2}{|c|}{ Group II } & \multirow{2}{*}{\multicolumn{2}{|c|}{$t$ value }} \\
\hline & & & \multirow{2}{*}{$\begin{array}{r}M \\
4.1\end{array}$} & \multirow{2}{*}{$\frac{S \boldsymbol{D}}{0.77}$} & \multirow{2}{*}{$\frac{M}{2.4}$} & \multirow{2}{*}{$\frac{S D}{1.05}$} & & \\
\hline & & & & & & & 29.91 & $* * *$ \\
\hline Q2 & 3.5 & 1.04 & 4.3 & 0.66 & 2.5 & 0.96 & 33.10 & $* * *$ \\
\hline Q3 & 3.8 & 1.11 & 4.4 & 0.81 & 3.1 & 1.18 & 20.14 & $* * *$ \\
\hline Q4 & 3.5 & 1.26 & 4.0 & 1.17 & 2.9 & 1.27 & 13.54 & $* * *$ \\
\hline Q5 & 3.8 & 1.06 & 4.6 & 0.66 & 3.0 & 1.15 & 25.44 & $* * *$ \\
\hline Q6 & 4.2 & 1.04 & 4.7 & 0.59 & 3.7 & 1.27 & 16.96 & $* * *$ \\
\hline Q7 & 3.6 & 1.06 & 4.4 & 0.65 & 2.6 & 1.03 & 32.70 & $* * *$ \\
\hline Q8 & 3.7 & 1.13 & 4.4 & 0.82 & 3.0 & 1.22 & 19.84 & $* * *$ \\
\hline Q9 & 3.4 & 1.07 & 4.3 & 0.71 & 2.4 & 0.95 & 34.40 & $* * *$ \\
\hline Q10 & 3.2 & 1.36 & 4.0 & 1.15 & 2.4 & 1.30 & 19.67 & $* * *$ \\
\hline Q11 & 4.3 & 0.94 & 4.8 & 0.44 & 3.5 & 1.11 & 24.17 & $* * *$ \\
\hline
\end{tabular}


Table 2. Cont.

\begin{tabular}{|c|c|c|c|c|c|c|c|c|}
\hline \multirow{3}{*}{$\frac{\text { Life skill }}{\text { Q12 }}$} & \multirow{3}{*}{\begin{tabular}{r}
\multicolumn{1}{c}{$\boldsymbol{M}$} \\
3.2
\end{tabular}} & \multirow{3}{*}{$\begin{aligned} S D \\
1.12\end{aligned}$} & \multicolumn{2}{|c|}{ Group I } & \multicolumn{2}{|c|}{ Group II } & \multirow{2}{*}{\multicolumn{2}{|c|}{$t$ value }} \\
\hline & & & \multirow{2}{*}{$\begin{array}{c}\boldsymbol{M} \\
4.2\end{array}$} & \multirow{2}{*}{$\begin{array}{r}S D \\
0.75\end{array}$} & \multirow{2}{*}{$\begin{array}{c}\boldsymbol{M} \\
2.1\end{array}$} & \multirow{2}{*}{$\frac{S D}{0.90}$} & & \\
\hline & & & & & & & 38.12 & $* * *$ \\
\hline Q13 & 3.7 & 1.20 & 4.4 & 0.90 & 3.0 & 1.25 & 20.22 & $* * *$ \\
\hline Q14 & 4.1 & 1.10 & 4.7 & 0.57 & 3.2 & 1.24 & 25.23 & $* * *$ \\
\hline Q15 & 3.6 & 1.10 & 4.4 & 0.69 & 2.7 & 1.05 & 30.27 & $* * *$ \\
\hline Q16 & 3.4 & 1.13 & 4.4 & 0.69 & 2.4 & 0.99 & 35.76 & $* * *$ \\
\hline Q17 & 3.8 & 1.16 & 4.6 & 0.67 & 2.8 & 1.15 & 29.19 & $* * *$ \\
\hline Q18 & 3.8 & 1.05 & 4.5 & 0.72 & 3.0 & 1.13 & 23.31 & $* * *$ \\
\hline Q19 & 4.3 & 0.96 & 4.8 & 0.52 & 3.6 & 1.17 & 19.77 & $* * *$ \\
\hline Q20 & 3.8 & 1.08 & 4.5 & 0.74 & 3.0 & 1.15 & 23.76 & $* * *$ \\
\hline Q21 & 4.1 & 1.03 & 4.6 & 0.67 & 3.5 & 1.16 & 19.22 & $* * *$ \\
\hline Q22 & 3.7 & 1.18 & 4.5 & 0.73 & 2.8 & 1.22 & 25.56 & $* * *$ \\
\hline Q23 & 3.8 & 1.12 & 4.5 & 0.73 & 3.1 & 1.21 & 22.59 & $* * *$ \\
\hline Q24 & 3.5 & 1.07 & 4.4 & 0.62 & 2.5 & 0.95 & 37.46 & $* * *$ \\
\hline Q25 & 3.9 & 1.07 & 4.6 & 0.68 & 3.0 & 1.12 & 26.00 & $* * *$ \\
\hline Q26 & 3.7 & 1.05 & 4.5 & 0.63 & 2.8 & 1.02 & 31.27 & $* * *$ \\
\hline Q27 & 4.0 & 0.98 & 4.6 & 0.63 & 3.3 & 1.04 & 24.82 & $* * *$ \\
\hline Q28 & 3.7 & 1.17 & 4.6 & 0.72 & 2.7 & 1.11 & 30.37 & $* * *$ \\
\hline Q29 & 3.3 & 1.04 & 4.3 & 0.66 & 2.3 & 0.87 & 39.13 & $* * *$ \\
\hline Q30 & 3.9 & 1.03 & 4.6 & 0.57 & 2.9 & 1.00 & 33.23 & $* * *$ \\
\hline Q31 & 3.3 & 1.12 & 4.1 & 0.84 & 2.4 & 1.00 & 29.13 & $* * *$ \\
\hline Q32 & 3.8 & 1.14 & 4.4 & 0.89 & 3.1 & 1.23 & 18.85 & $* * *$ \\
\hline Q33 & 3.5 & 1.13 & 4.4 & 0.82 & 2.6 & 1.03 & 28.89 & $* * *$ \\
\hline Q34 & 3.6 & 1.24 & 4.5 & 0.75 & 2.7 & 1.19 & 28.72 & $* * *$ \\
\hline Q35 & 3.7 & 1.18 & 4.3 & 0.92 & 3.0 & 1.24 & 18.54 & $* * *$ \\
\hline Q36 & 3.4 & 1.18 & 4.3 & 0.87 & 2.5 & 1.04 & 28.79 & $* * *$ \\
\hline Q37 & 3.4 & 1.29 & 4.0 & 1.11 & 2.6 & 1.22 & 18.94 & $* * *$ \\
\hline Q38 & 3.8 & 1.01 & 4.5 & 0.70 & 3.0 & 1.01 & 26.74 & $* * *$ \\
\hline Q39 & 3.6 & 1.18 & 4.5 & 0.73 & 2.7 & 1.15 & 28.95 & $* * *$ \\
\hline Q40 & 4.2 & 1.17 & 4.8 & 0.58 & 3.5 & 1.38 & 19.05 & $* * *$ \\
\hline Q41 & 3.9 & 1.12 & 4.7 & 0.62 & 2.9 & 1.14 & 30.27 & $* * *$ \\
\hline Q42 & 3.4 & 1.04 & 4.4 & 0.63 & 2.5 & 0.94 & 36.64 & $* * *$ \\
\hline Q43 & 3.2 & 1.14 & 4.3 & 0.72 & 2.2 & 0.90 & 39.30 & $* * *$ \\
\hline Q44 & 3.5 & 1.17 & 4.4 & 0.78 & 2.5 & 1.02 & 31.39 & $* * *$ \\
\hline Q45 & 3.9 & 1.12 & 4.5 & 0.75 & 3.1 & 1.22 & 22.05 & $* * *$ \\
\hline Q46 & 4.2 & 1.05 & 4.7 & 0.66 & 3.5 & 1.25 & 18.73 & $* * *$ \\
\hline Q47 & 3.5 & 1.14 & 4.4 & 0.73 & 2.5 & 1.02 & 32.67 & $* * *$ \\
\hline Q48 & 4.0 & 1.00 & 4.6 & 0.65 & 3.3 & 1.06 & 23.23 & $* * *$ \\
\hline Q49 & 3.8 & 1.13 & 4.5 & 0.72 & 3.0 & 1.23 & 22.62 & $* * *$ \\
\hline Q50 & 3.5 & 1.04 & 4.3 & 0.73 & 2.6 & 0.91 & 32.28 & $* * *$ \\
\hline Q51 & 3.5 & 1.22 & 4.3 & 0.86 & 2.6 & 1.20 & 25.36 & $* * *$ \\
\hline Q52 & 3.0 & 1.34 & 3.2 & 1.47 & 2.9 & 1.28 & 3.62 & $* * *$ \\
\hline Q53 & 3.3 & 1.14 & 4.2 & 0.86 & 2.3 & 1.00 & 31.14 & $* * *$ \\
\hline Q54 & 3.8 & 1.27 & 4.3 & 1.04 & 3.2 & 1.34 & 15.07 & $* * *$ \\
\hline Q55 & 3.3 & 1.26 & 3.8 & 1.21 & 2.7 & 1.20 & 13.75 & $* * *$ \\
\hline
\end{tabular}


Table 2. Cont.

\begin{tabular}{|c|c|c|c|c|c|c|c|c|}
\hline \multirow{3}{*}{$\frac{\text { Life skill }}{\text { Q56 }}$} & \multirow{3}{*}{\begin{tabular}{r}
\multicolumn{1}{c}{} \\
3.6
\end{tabular}} & \multirow{3}{*}{$\begin{array}{r}S D \\
1.11\end{array}$} & \multicolumn{2}{|c|}{ Group I } & \multicolumn{2}{|c|}{ Group II } & \multirow{2}{*}{\multicolumn{2}{|c|}{$t$ value }} \\
\hline & & & \multirow{2}{*}{$\begin{array}{c}\boldsymbol{M} \\
4.4\end{array}$} & \multirow{2}{*}{$\begin{array}{r}\boldsymbol{S D} \\
0.68\end{array}$} & \multirow{2}{*}{$\begin{array}{c}\boldsymbol{M} \\
2.6\end{array}$} & \multirow{2}{*}{$\begin{array}{r}S D \\
1.07\end{array}$} & & \\
\hline & & & & & & & 31.63 & $* * *$ \\
\hline Q57 & 3.7 & 1.19 & 4.4 & 0.86 & 3.1 & 1.22 & 19.81 & $* * *$ \\
\hline Q58 & 3.7 & 1.15 & 4.4 & 0.82 & 2.9 & 1.18 & 22.70 & $* * *$ \\
\hline Q59 & 3.8 & 1.21 & 4.4 & 0.90 & 3.2 & 1.38 & 15.01 & $* * *$ \\
\hline Q60 & 3.6 & 1.12 & 4.5 & 0.69 & 2.6 & 1.07 & 31.40 & $* * *$ \\
\hline
\end{tabular}

\section{Results and Discussion}

\subsection{Exploratory Factor Analysis}

In the preliminary study, 60 items were subjected to an exploratory factor analysis using the maximum likelihood method and promax rotation. To determine the stability of each item, factor analysis was conducted with the criterion of an eigenvalue greater than one. Items with low factor loadings or eigenvalues less than 0.40 were removed. In addition, the factorial analysis was reperformed in order to ease interpretation and to increase the eigenvalue of the factors. As a result, 24 items constituting seven factors were extracted (Table 3). Percentages of variance explained by the seven factors were as follows: 11.38\% for Factor 1, 8.49\% for Factor 2, 7.64\% for Factor 3, 9.43\% for Factor 4, 7.58\% for Factor 5, 5.61\% for Factor 6, and 8.10\% for Factor 7.

For the constructs, the factors were named after reviewing common keywords of each item. As shown in Table 3, the first factor comprised six items: "able to solve a problem by using reasoning," "able to share a difficult problem with a friend," "able to arrange the order of problem-solving," "able to examine several problem-solving ideas," "able to arrange an order of priority," and "able to examine and compare various opinions from friends." Accordingly, the keywords of this factor were "convey information clearly," "problem-solving," and "comparing ideas and opinions." From these keywords, six skills were then described and used as a factor in order to examine the idea of a life skill. The first factor was then named "problem-solving or synthesis" because it incorporated problemsolving and judgment skills.

Similar to the previous factor, the second factor comprised three items: "having a friend to share or consult with," "able to freely share with friends when facing trouble," and "able to honestly discuss various things with a friend." These items were designed to describe communication skills that maintain friendships among children. This second factor was described as "relationship with friends."

The third factor comprised three items: "able to be polite to older people," "able to use the polite form (honorific expression) with older people," and "able to carefully choose words when talking to new people." The keywords of this factor were "older people," "someone you meet for the first time," "manners," "honorific expression," and "choice of words." This factor measures children's ability to use their manners to respect others, including older people, which is very important in Japanese culture and might be counted as an indispensable skill in Japanese society. Generally, the 
third factor was concerned with using propriety and politeness with others and was described as "personal manners."

The fourth factor comprised three items: "able to think about the future without prompting from parents and teachers," "able to determine what must be done in order to reach a chosen future career," and "able to consider potential self-development for the future." The keywords for the fourth factor were decision-making ability for the future; therefore, this factor was named "decisionmaking and future planning."

The fifth factor comprised three items: "able to do homework even though tired," "able to devise own plan for doing homework," and "able to study at home without being told (self-learning)." The keywords for this factor were "keep learning even though tired," "individual learning capability," and "studying without being told." Therefore, the factor was named "self-learning."

The sixth factor comprised three items: "able to collect study materials for independent study," "able to collect many materials while doing activities," and "able to find books from the library or other sources and summarize them in self-study." These items assessed the ability to collect and use books or materials as sources of information for their study. Thus, this factor was described as "collecting and using information."

Finally, the seventh factor comprised three items: "able to lead others in activities with friends," "able to summarize everyone's opinions in a discussion," and "able to lead people through words and actions." The keywords for this factor were "leader," "summarizing others" opinions," and "organizing and leading other people." Therefore, this factor was termed "leadership."

As a result of this analysis, the Multidimensional Scale of Life Skills in Late Childhood comprises seven subscales and 24 items. 
Table 3. Factor matrix of the Multidimensional Scale of Life Skills in Late Childhood (promax rotation, $n=1888$ ).

\begin{tabular}{|c|c|c|c|c|c|c|c|c|c|c|c|c|}
\hline \multirow{2}{*}{ Factor } & \multirow{2}{*}{ No. } & \multirow{2}{*}{ Description } & \multirow{2}{*}{$M$} & \multirow{2}{*}{$S D$} & \multicolumn{7}{|c|}{ Factor loading } & \multirow{2}{*}{ Communality } \\
\hline & & & & & F1 & F2 & F3 & F4 & F5 & F6 & F7 & \\
\hline \multirow{6}{*}{$\begin{array}{l}\text { Problem- } \\
\text { solving/ } \\
\text { synthesis }\end{array}$} & 42 & Able to solve a problem by using reasoning & 3.43 & 1.04 & .803 & -.027 & -.114 & .044 & .012 & .036 & -.016 & .589 \\
\hline & 43 & Able to share a difficult problem with a friend & 3.22 & 1.14 & .777 & .020 & -.007 & -.169 & -.042 & .020 & .137 & .563 \\
\hline & 16 & Able to arrange the order of problem-solving & 3.43 & 1.13 & 686 & -.061 & .013 & -.003 & .012 & .122 & -.048 & .497 \\
\hline & 29 & Able to examine several problem-solving ideas & 3.28 & 1.04 & 682 & -.090 & .024 & .047 & -.032 & .081 & .091 & 600 \\
\hline & 56 & Able to arrange an order of priority & 3.56 & 1.11 & .654 & .119 & -.014 & .073 & -.028 & .023 & -.154 & .457 \\
\hline & 24 & Able to examine and compare various opinions from friends & 3.49 & 1.07 & .556 & .036 & .021 & -.012 & .002 & .092 & .116 & .538 \\
\hline \multirow{3}{*}{$\begin{array}{l}\text { Relationship } \\
\text { with friends }\end{array}$} & 40 & Having a friend to share or consult with & 4.18 & 1.17 & -.159 & .834 & -.043 & -.042 & -.037 & .109 & -.028 & .476 \\
\hline & 34 & Able to freely share with friends when facing a problem & 3.65 & 1.24 & .075 & .807 & -.092 & -.076 & -.049 & .132 & -.039 & .567 \\
\hline & 5 & Able to honestly discuss various things with a friend & 3.84 & 1.06 & -.091 & 620 & -.028 & -.014 & .027 & .247 & .028 & .457 \\
\hline \multirow{3}{*}{$\begin{array}{l}\text { Personal } \\
\text { manners }\end{array}$} & 25 & Able to be polite to older people & 3.87 & 1.07 & .052 & -.030 & .901 & -.068 & -.007 & -.011 & -.066 & .702 \\
\hline & 3 & Able to use the polite form (honorific expression) with older people & 3.80 & 1.11 & -.059 & -.062 & .804 & -.015 & -.037 & .046 & -.039 & .498 \\
\hline & 11 & Able to carefully choose words when talking to new people & 4.26 & 0.94 & -.103 & .074 & .581 & .032 & .043 & .013 & .108 & .451 \\
\hline \multirow{3}{*}{$\begin{array}{l}\text { Decision- } \\
\text { making and } \\
\text { future planning }\end{array}$} & 14 & Able to think about the future without prompting from parents and teachers & 4.09 & 1.10 & -.163 & -.054 & -.020 & .798 & .062 & -.011 & .063 & .491 \\
\hline & 28 & Able to determine what must be done to reach a chosen future career & 3.71 & 1.17 & .079 & -.069 & .012 & .723 & -.073 & .008 & -.006 & .501 \\
\hline & 41 & Able to consider potential self-development for the future & 3.90 & 1.12 & .149 & .032 & -.105 & .588 & -.045 & .022 & .055 & .474 \\
\hline \multirow{3}{*}{ Self-learning } & 6 & Able to do homework even though tired & 4.25 & 1.04 & -.165 & .040 & -.004 & -.088 & .717 & .043 & .011 & .381 \\
\hline & 17 & Able to devise own plan for doing homework & 3.75 & 1.16 & .170 & -.063 & -.062 & .031 & .695 & .001 & -.048 & .551 \\
\hline & 22 & Able to study at home without being told (self-learning) & 3.70 & 1.18 & .027 & -.060 & .017 & .014 & .692 & -.045 & .033 & .477 \\
\hline \multirow{3}{*}{$\begin{array}{l}\text { Collecting and } \\
\text { using } \\
\text { information }\end{array}$} & 7 & Able to collect study materials in self-study & 3.58 & 1.06 & .170 & .046 & .043 & .009 & .029 & .633 & -.011 & 644 \\
\hline & 9 & Able to collect many materials while doing activities & 3.37 & 1.07 & .185 & -.013 & .126 & .095 & -.039 & .473 & .068 & .570 \\
\hline & 2 & $\begin{array}{l}\text { Able to find books from the library and other sources and summarize them } \\
\text { in self-study }\end{array}$ & 3.48 & 1.04 & .249 & -.038 & .001 & .034 & .110 & .447 & .041 & .533 \\
\hline \multirow{11}{*}{ Leadership } & 1 & Able to lead others while doing activities with friends & 3.31 & 1.12 & .025 & -.009 & -.074 & .074 & -.022 & .093 & .708 & .600 \\
\hline & 12 & Able to summarize everyone's opinions in a discussion & 3.19 & 1.12 & .340 & -.057 & .069 & -.082 & -.030 & .133 & .491 & 617 \\
\hline & 53 & Able to lead others through words and actions & 3.28 & 1.14 & .337 & .024 & -.085 & .001 & .091 & -.086 & .463 & .519 \\
\hline & & Contribution ratio $(\%)$ & & & 11.4 & 8.5 & 7.6 & 9.4 & 7.6 & 5.6 & 8.1 & 43.6 \\
\hline & & & & & $\mathrm{F} 1$ & $\mathrm{~F} 2$ & F3 & $\mathrm{F} 4$ & F5 & F6 & F7 & \\
\hline & & & & $\mathrm{F} 1$ & & .662 & .660 & .775 & .679 & .576 & .717 & \\
\hline & & & & $\mathrm{F} 2$ & & & .595 & 660 & .565 & .303 & .594 & \\
\hline & & Correlation between factors & & F3 & & & & .637 & .570 & .373 & .492 & \\
\hline & & & & $\mathrm{F} 4$ & & & & & .589 & .505 & .611 & \\
\hline & & & & F5 & & & & & & .477 & .487 & \\
\hline & & & & F6 & & & & & & & .522 & \\
\hline
\end{tabular}

Note: Both values of correlation between factors were $p<.001$ 


\subsection{Reliability and Validity of the Scale}

Each subscale was examined with the test-retest reliability method and computing $\alpha$-coefficients in order to verify their internal reliability. Reliability coefficients indicated that the values of each subscale remained constant, as shown in Table 4. Thus, values of each subscale remained constant as evidenced by their test-retest reliability and internal consistency (Table 4).

Table 4. Reliability analysis of subscales.

\begin{tabular}{lcc}
\hline \multicolumn{1}{c}{ Factor } & a-coefficient & Test-retest reliability coefficient \\
\hline Problem-solving/synthesis & .87 & .77 \\
Relationship with friends & .75 & .79 \\
Personal manners & .77 & .78 \\
Decision-making and future planning & .74 & .75 \\
Self-learning & .71 & .68 \\
Collecting and using information & .81 & .74 \\
Leadership & .79 & .78 \\
\hline
\end{tabular}

Note: 1) Both values of test-retest reliability coefficient were $p<.001$

2) Internal consistency: $n=1,888$; test-retest reliability: $n=144$

In order to examine the construct validity of the scale, a confirmatory factor analysis was also conducted. The indexes used were GFI, AGFI, CFI, and RMSEA. The GFI, AGFI, and CFI fit indices ranged from 0 to 1 . A GFI value greater than 0.9 was considered as an acceptable model fit [19]. Moreover, RMSEA less than 0.8 was considered an indicator of excellent fit between the specified model and the data [20]. Goodness-of-fit results $(\mathrm{GFI}=0.952$, AGFI $=0.937, \mathrm{CFI}=0.966$, RMSEA $=0.016$ ) were found to be satisfactory.

\subsection{About Gender}

Mean values and standard deviations for each subscale were examined with respect to gender differences of the respondents (Table 5). Results showed that girls generally scored higher than boys did. The effect size ( $d$-score) of gender differences for the total score was 0.11 . Of these subscales, only Subscale 2 (relationship with friends) had a $d$-score more than 0.20 , indicating that boys and girls may have different views on friendships and reflecting a gap in social-skill levels between them. However, since the $d$-score for the overall total score was lower than 0.20 , the differences might not have been affected by the sample size. Moreover, consistent with the findings of Iida and Ishikuma [12], data variance was observed to be lower in girls' scores as compared with the boys' scores. Previous studies have reported that girls have a higher level of social skills than do boys [21, 22]. In the present study, "relationship with friends" and "personal manners" factors were also found to correspond to gender. 
Table 5. Gender differences on the Multidimensional Scale of Life Skills in Late Childhood.

\begin{tabular}{lcccc}
\hline \multicolumn{1}{c}{ Subscale/Sex } & $\boldsymbol{n}$ & $\boldsymbol{M}$ & $\boldsymbol{S D}$ & $\boldsymbol{d}$-score \\
\hline Problem-solving/synthesis & & & & \\
Boy & 924 & 20.27 & 5.28 & 0.06 \\
Girl & 964 & 20.57 & 4.88 & \\
Relationship with friends & & & & \\
Boy & 924 & 11.30 & 2.92 & 0.25 \\
Girl & 964 & 12.01 & 2.69 & \\
Personal manners & & & & \\
Boy & 924 & 11.74 & 2.72 & 0.06 \\
Girl & 964 & 12.11 & 2.44 & \\
Decision-making and future planning & & & \\
Boy & 924 & 11.58 & 2.92 & 0.08 \\
Girl & 964 & 11.81 & 2.56 & \\
Self-learning & & & & \\
Boy & 924 & 11.43 & 2.81 & 0.20 \\
Girl & 964 & 11.96 & 2.56 & \\
Collecting and using information & & & \\
Boy & 924 & 10.30 & 2.80 & 0.10 \\
Girl & 964 & 10.56 & 2.58 & \\
Leadership & & & & \\
Boy & 924 & 9.75 & 2.89 & 0.02 \\
Girl & 964 & 9.80 & 2.76 & \\
Total Score & & & & \\
Boy & 924 & 86.37 & 17.25 & \\
Girl & 964 & 88.82 & 15.69 & 0.11 \\
\hline
\end{tabular}

\subsection{Relationship between Multidimensional Life Skills and "zest for living"}

In the present study, we examined 24 items and seven factors: "problem-solving/synthesis," "relationship with friends," "personal manners," "decision-making and future planning," "selflearning," "collecting and using information," and "leadership." These seven factors were adopted from eight factors of a life-skills scale for university students reported in a previous study [9], and the correlation between these factors was high. Late childhood, as mentioned before, can be classified in undifferentiated developmental stages that are comparable to university life. Moreover, our description of three of the factors was adopted from their original descriptions ("relationship with friends," "personal manners," and "leadership"), whereas other factors were used with some modifications.

The concepts assessed by the Multidimensional Scale of Life Skills in Late Childhood are similar to the "zest for living" concept. According to the "Guidance for promotion of career education for elementary, junior high, and senior high schools" issued by the Ministry of Education, Culture, Sports, Science and Technology, there are four important skills for endorsing self-actualization and a sense of vocation in students: "ability to form relationships," "ability to use information," "ability to plan the future," and "decision-making ability." In the present study, these terms were described as "relationship with friends," "collecting and using information," and "decision-making and future 
planning" [23]. Our subscales corresponded well with the career education curriculum of the Ministry of Education, Culture, Sports, Science and Technology.

The "zest for living" concept was fully implemented as a core philosophy for elementary schools in 2011 and for junior high schools in 2012. Until recently, there was little information available on implementing the "zest for living" concept; thus, this study is an attempt to provide needed information. The Ministry of Education, Culture, Sports, Science and Technology report also mentioned that development of a multidimensional scale of life skills for domestic use is a necessity [2]. Our proposed scale might promote understanding of the behaviors and inner motivations of children in daily life.

Moreover, a focus of the Multidimensional Scale of Life Skills in Late Childhood was to identify skills that could be improved to increase inner motivation in daily-life situations. For this purpose, this scale should be conducted with a teamwork approach involving both children and teachers. Application of this multidimensional scale will be very important for future empirical studies.

\subsection{Future Development}

In the future, corroboration of the validity of the scale and examination of its practical applications might be researched further. In addition, the number of items in each subscale and their content might be reexamined. The first factor, "problem solving or synthesis," consisted of six items, whereas the other factors consisted of only three items, which could not clearly describe the factor. Therefore, evaluation of these subscales should be interpreted carefully. The Multidimensional Scale of Life Skills in Late Childhood should be reconfirmed with other appropriate evaluation methods, as described by Shimamoto and Ishii [9]. Moreover, for various reasons, several items were excluded from the analysis because improvements were needed. In addition, other indicators such as mental health and loneliness scales, as reported by previous studies, might be considered for use in evaluating the validity of the scale. Despite these limitations, the present study can be considered a milestone in developing a broader construct of multidimensional life skills in our future work, including more subscales and variance of multilevel effect of school regions.

\section{Conclusions}

The present study examined the reliability and validity of the Multidimensional Scale of Life Skills in Late Childhood, developed from a survey comprising 60 life-skills items and conducted with 1,888 Japanese children (924 boys and 964 girls) aged 9-12 years. The exploratory factor analysis resulted in extraction of seven factors consisting of 24 items. Subscales include problem-solving/synthesis, relationship with friends, personal manners, decision-making and future planning, self-learning, collecting and using information, and leadership. The reliability of the scale was evaluated with Cronbach's alpha coefficient and test-retest methods. The alpha coefficients of each subscale ranged from 0.71 to 0.87 , and the reliability coefficient values ranged from 0.68 to 0.79 . The construct validity of the scale was verified using confirmatory factor analysis, including GFI, AGFI, CFI, and RMSEA indices. The goodness-of fit indices $(\mathrm{GFI}=0.952$, AGFI $=0.937, \mathrm{CFI}=0.966$, $\mathrm{RMSEA}=0.016$ ) revealed satisfactory values. Regarding gender, girls' scores on five of seven subscales were consistently higher than were boys' scores, and individual variations among girls' scores were 
relatively low. This result confirmed the coexistence validity of the scale. Although the number of items included in each factor was low, the reliability and validity of the Multidimensional Scale of Life Skills in Late Childhood could be generally measured. Further evaluation of the validity of scale and its practical application in schools can be examined in future work.

Postscript. The authors acknowledge a critical review of one referee regarding the use of three-item scales in developing the Multidimensional Scale of Life Skills in Late Childhood. The referee suggested that constructing at least 8-10 items for each scale is the best practice in developing a comprehensive scale. It was also suggested that the scales might be administered at different times to reduce the time load on respondents. However, the present survey was conducted with elementary school students in the 4th, 5th, and 6th grades, and the children's fatigue could have caused bias when answering questions. Moreover, in Japan, conducting survey research with several steps (multiple tests) is almost impossible due to tight lesson schedules and other regular classroom activities. Given this limitation, three-item scales were developed for planning ability, collecting and using information, self-respect, positive thinking, empathy, leadership, sensitivity, personal manners, self-learning, and career decision-making. In addition to the 60 life-skills items, we developed six items for health and physical fitness, seven items for problem-solving and decision making, and ten items for interpersonal communication and human relations, resulting in a valid psychological measurement for the Multidimensional Scale of Life Skills in Late Childhood. Accordingly, the present paper can be a milestone for developing a broader and more comprehensive construct of life skills incorporating different viewpoints.

\section{Acknowledgements}

We wish to express our gratitude to all those who participated in the study: students, teachers, and parents of respondents.

\section{References}

1. Japanese Ministry of Education, Culture, Sports, Science and Technology. FY2007 investigation into the student guidance of student behavior problems (in Japanese). Elementary Education Bulletin 2008, 843, 79-85.

2. Iida, J.; Ishikuma, T. Development of scales measuring skills in junior high school students: An overview of studies (in Japanese with English abstract). Tsukuba Psychological Research 2003, 26, 213-228.

3. World Health Organization. Life skills education in schools. Programme on Mental Health, World Health Organization: Geneva, Switzerland, 1997; pp. 11-30.

4. Landman, J.T.; Irvin, L.K.; Halpern, A.S. Measuring life skills of adolescents: Tests for everyday living (TEL). Measurement and Evaluation in Guidance 1980, 13, 95-106.

5. Brooks, D.K. Jr. A life skills taxonomy: Defining elements of effective functioning through the use of the Delphi technique. Doctoral dissertation, University of Georgia, Athens, USA, 1984.

6. Darden, C.A.; Ginter, E.J.; Gazda, G.M. Life skills development scale-adolescent form: The theoretical and therapeutic relevance of life skills. Journal of Mental Health Counseling 1996, 18, 142-163. 
7. Kadish, T. E., Glaser, B.A.; Calhoun, G.B.; Ginter, E.J. Identifying the developmental strengths of juvenile offenders: Assessing four life skills dimensions. Journal of Addictions and Offender Counseling 2001, 21, 85-95.

8. Picklesimer, B.K.; Miller, T.K. Life skills development inventory-college form: An assessment measure. Journal of College Student Development 1998, 39, 100-110.

9. Shimamoto, K.; Ishii, M. Development of a daily life skills scale for college students (in Japanese with English abstract). Japanese Journal of Educational Psychology 2006, 54, 211-221.

10. Danish, S.J.; Petitpas, A.J.; Hale, B.D. Psychological interventions: A life development model. In Sport psychology interventions; Murphy, S.M., Ed.; Human Kinetics: Champaign, Illinois, USA, 1995; pp. 19-38.

11. Ueno, K.; Nakagomi, S. A study on the acquisition of life skills through the participation in athletic club (in Japanese with English abstract). Japanese Journal of Physical Education 1998, $43,33-42$.

12. Iida, J.; Ishikuma, T. School-life skills scale: Development of a junior high school student form (in Japanese with English abstract). Japanese Journal of Educational Psychology 2002, 50, 225236.

13. Gresham, F.M.; Elliott, S.N. Assessment and classification of children's social skills: A review of methods and issues. School Psychology Review 1984, 13, 292-301.

14. Japanese Ministry of Education, Culture, Sports, Science and Technology. Fundamental view of the revised government guidelines for teaching (in Japanese). Secondary Education Bulletin 2008, $861,10-15$.

15. Minagawa, K. Integrated Study on Life Skills Education Training (In Japanese). Meijitoshoshuppan Corporation: Tokyo, Japan, 1999; pp. 12-13.

16. Japanese Ministry of Education, Culture, Sports, Science and Technology. The first report of the Central Council for Education (in Japanese). Secondary Education Bulletin 1996, 677, 96-98.

17. Japanese Ministry of Education, Culture, Sports, Science and Technology. The improvement of the government guidelines for teaching of kindergarten, elementary school, junior high school, high school, and special support school (in Japanese). Secondary Education Bulletin 2008, 861, 97-106.

18. Erikson, E.H. Childhood and Society, $2^{\text {nd }}$ Ed. Norton: New York, USA, 1963.

19. Jöreskog, K.G.; Sörbom, D. Liseral8: Structural Equation Modeling with the SIMPLIS Command Language. Lawrence Erlbaum Associates: Hillsdale, New Jersey, USA, 1993; pp. 1-12.

20. Yamamoto, K. Covariance structural analysis and its application. In Covariance structural analysis and analytical cases using Amos (in Japanese); Yamamoto, K., Onodera, T., Eds.; Nakanishiya Publisher: Kyoto, Japan, 2000; pp. 1-22.

21. Walker, S. Gender differences in the relationship between young children's peer-related social competence and individual differences in theory of mind. The Journal of Genetic Psychology 2005, 166, 297-312.

22. Teodoro, M.L.M.; Käppler, K.C.; Rodrigues, J.L.; de Freitas, P.M.; Haase, V.G. The Matson Evaluation of Social Skills with Youngsters (MESSY) and its adaptation for Brazilian children and adolescents. Interamerican Journal of Psychology 2005, 39, 239-246. 
23. Japanese Ministry of Education, Culture, Sports, Science and Technology. Fostering the work attitudes, from the working students' point of view (in Japanese). Report on the Comprehensive Research on Cooperation in Career Education Promotion; Japan, 2004; pp. 1-41.

(C) 2013 by the authors; licensee MDPI, Basel, Switzerland. This article is an open access article distributed under the terms and conditions of the Creative Commons Attribution license (http://creativecommons.org/licenses/by/3.0/). 